Check for updates

Cite this: RSC Adv., 2018, 8, 34773

Received 26th July 2018

Accepted 27th September 2018

DOI: $10.1039 / c 8 r a 06327 c$

rsc.li/rsc-advances

\title{
Lecithin-chitosan-TPGS nanoparticles as nanocarriers of (-)-epicatechin enhanced its anticancer activity in breast cancer cells
}

\author{
Adriana Guadalupe Perez-Ruiz, (D) a Adriana Ganem, ${ }^{\mathrm{b}}$ Ivonne María Olivares- \\ Corichi iD a and José Rubén García-Sánchez iD *a
}

\begin{abstract}
Natural compounds such as (-)-epicatechin show a variety of biological properties including anticancer activity. Nonetheless, (-)-epicatechin's therapeutic application is limited due to its low water solubility and sensitivity to oxygen and light. Additionally, previous studies have reported that the encapsulation of flavonoids in nanoparticles might generate stable deliverable forms, which improves the availability and solubility of the bioactive compounds. The aims of this study were to generate (-)-epicatechin-loaded lecithin-chitosan nanoparticles (EC-LCT-NPs) by molecular self-assembly and to assess their cytotoxic potential against breast cancer cells. Various parameters were measured to characterize the EC-LCTNPs including size, polydispersity index (Pdl), zeta potential, morphology and entrapment efficiency. The results showed that the mean particle size of the EC-CLT-NPs was $159 \pm 2.23 \mathrm{~nm}$ (Pdl, 0.189), and the loading and entrapment efficiencies of (-)-epicatechin were $3.42 \pm 0.85 \%$ and $56.1 \pm 3.9 \%$, respectively. The cytotoxic effect of the EC-CLT-NPs was greater than that of free (-)-epicatechin on breast cancer cell lines (MCF-7, MDA-MB-231, MDA-MB-436 and SK-Br3). Indeed, EC-LCT-NPs showed an IC 50 that was four-fold lower $(85 \mu \mathrm{M})$ than free $(-)$-epicatechin $(350 \mu \mathrm{M})$ and showed selectivity to cancerous cells. This study demonstrated that encapsulating (-)-epicatechin into lecithin-chitosan nanoparticles opens new options for breast cancer treatment.
\end{abstract}

\section{Introduction}

Polyphenols are natural compounds that contain multiple phenolic units in their chemical structure. Polyphenols are comprised of several natural compounds that include flavonoids. Interestingly, the consumption of natural products with high flavonoids content has been associated with a decreased risk of developing different pathologies. For example, green tea consumption is associated with a protection against cancer and this effect is attributed to flavonoid epigallocatechin-3-gallate (EGCG), the major constituent of green tea. ${ }^{1}$ Although EGCG is considered the main molecule of the anticancer activity, toxicological studies revealed a hepatotoxicity as a critical effect of the molecule and a limitation to be used. ${ }^{2}$

Theobroma cacao is another natural product (cocoa and cocoa derived products (chocolate)) with high levels of polyphenols, where (-)-epicatechin constitutes the most abundant flavonoid. ${ }^{3,4}(-)$-Epicatechin also has shown anticancer activity, but a difference of EGCG have not shown any side effect. This

${ }^{a}$ Sección de Estudios de Posgrado e Investigación, Escuela Superior de Medicina del Instituto Politécnico Nacional, Ciudad de México, Mexico.E-mail: jrgarcias@ipn.mx ${ }^{b}$ Division de Estudios de Posgrado (Tecnología Farmacéutica), Facultad de Estudios Superiores Cuautitlán, Universidad Nacional Autónoma de Mexico, Cuautitlán Izcalli, Estado de Mexico, Mexico feature makes (-)-epicatechin a molecule interesting for the development of novel phytopharmaceuticals against cancer.

The molecular structure of (-)-epicatechin is shown in Fig. 1. (-)-epicatechin has been described to have antioxidant, ${ }^{5,6}$ antiinflammatory, ${ }^{7}$ cardiovascular $^{8}$ and anti-cancer ${ }^{9-11}$ properties, among others. Because several studies reported the anticancer activity of (-)-epicatechin, there is an interest in its use as

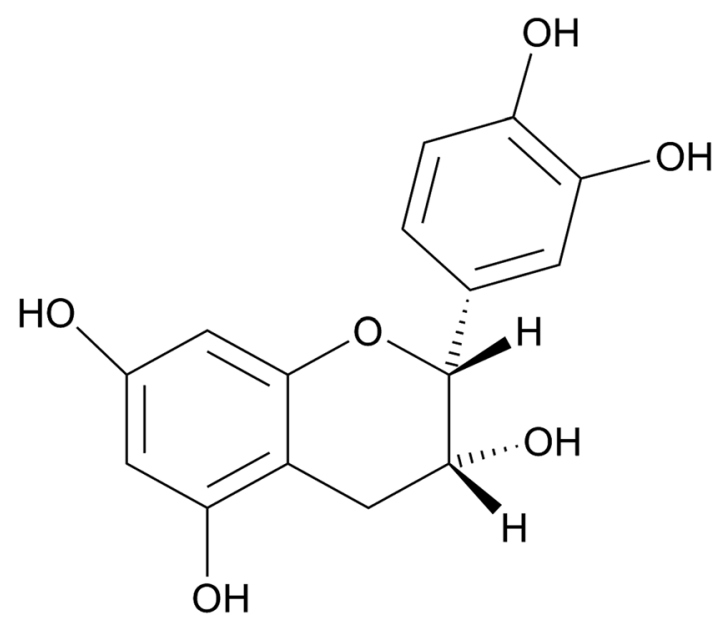

Fig. 1 Molecular structure of (-)-epicatechin. 
a therapeutic agent against cancer. However, (-)-epicatechin has limited water solubility, a high metabolism and sensitivity to oxygen and light, ${ }^{12}$ which diminish its activity. For these reasons, the generation of a system that carries, protects and as a consequence improves the action of (-)-epicatechin is of interest.

Various methods have been proposed for the encapsulation of flavonoids to generate stable deliverable forms. ${ }^{13-15}$ A nanoparticle is one of the chief options because it is a delivery system for poorly aqueous bioactive compounds that increase the availability and solubility of the bioactive compounds. Furthermore, nanoencapsulation also increases the stability of the compound and reduces possible side effects. On the other hand, different polymers including polylactic acid, albumin, gelatine and chitosan have been used in the preparation of nanoparticles. ${ }^{16}$ Indeed, chitosan, a polycationic polymer, has received considerable attention due to its biopharmaceutical properties such as biocompatibility, penetration enhancement, bioadhesion and biodegradability. ${ }^{17}$ In addition, it has been reported that the presence of $-\mathrm{NH}_{2}$ and $-\mathrm{OH}$ groups on chitosan allows for the generation of a positive charge in acidic conditions that can be used for surface modification or better coverage of active compounds. ${ }^{\mathbf{1 6}}$

On the other hand, lecithin a natural lipid mixture of phospholipids is incorporated as a stabilizer of the nanosystem. Lecithin in the nanosystem generates a three-dimensional network that immobilizes the contiguous. Lecithin has been used as a phospholipid-structured system for topical drug delivery, ${ }^{18}$ or in the preparation of various nanosystem delivery vehicles, such as micelle, liposomes, microemulsions and nanoparticles. Indeed, the potential of applications of lecithin has shown that is an excipient safe with biocompatibility. ${ }^{\mathbf{1 9 , 2 0}}$

D-alpha-tocopheryl polyethylene glycol 1000 succinate (TPGS) was included in the nanosystem because its acidification derivate to TPGS-COOH, a molecule accessible for conjugation with proteins and macromolecules. Furthermore, it has been reported that the conjugation of chitosan with TPGS can increase the drug solubility, stabilizes the nanoparticles, prolong the residence time by adhesion and retention of the delivery system at the cell surface and generates a drug releasing sustained. ${ }^{21}$

In the present study, we focused on the preparation and characterization of lecithin-chitosan nanoparticles as potential carriers of (-)-epicatechin. (-)-epicatechin-loaded lecithin-chitosan-TPGS nanoparticles (EC-LCT-NPs) were prepared by molecular self-assembly. The EC-LCT-NPs were characterized by assessing particle size, zeta potential, polydispersity index (PdI), entrapment efficiency (EE) and morphology. Furthermore, the anticancer activity of EC-LCTNPs was evaluated in different types of breast cancer cells and compared with free (-)-epicatechin.

\section{Materials and methods}

\section{Materials}

(-)-Epicatechin ( $\geq 90 \%$ purity), chitosan of $90 \%$ purity (medium molecular weight, MW 190-310 (75\% deacetylation), tocopherol, D- $\alpha$-tocopherol polyethylene glycol 1000 succinate (TPGS), methanol, ethanol, acetic acid and other chemicals were purchased from Sigma Aldrich-México (Toluca, state of México). Egg lecithin (Emulmetik 930TM) was obtained from Silanes Pharmaceutical Co. (Polanco, Mexico City).

\section{Methods}

Preparation of lecithin-chitosan and (-)-epicatechin-loaded lecithin-chitosan nanoparticles. Lecithin-chitosan nanoparticles were prepared by molecular self-assembly according to Sonvico et al. ${ }^{22}$ with modifications. Briefly, a solution of egg lecithin $8.75 \%(\mathrm{w} / \mathrm{v})$ was prepared in $96 \%$ ethanol. Nanoparticles were obtained by injecting $4 \mathrm{~mL}$ of the lecithin ethanol solution into $46 \mathrm{~mL}$ of a chitosan solution through plastic needle tubing (internal diameter $0.4 \mathrm{~mm}$ ) under mechanical agitation at $10000 \mathrm{rpm} \min ^{-1}$ for $15 \mathrm{~min}$ using Ultraturrax (Erika, USA). The chitosan solution was obtained by dissolving $10 \mathrm{mg}$ of chitosan in $50 \mathrm{~mL}$ of distilled water with $3 \%$ acetic acid and $1.5 \%$ TPGS $(\mathrm{w} / \mathrm{v})$. In the colloidal suspension, lecithin/ chitosan was present at a ratio of $38: 1(\mathrm{w} / \mathrm{w})$. After stirring, the $\mathrm{pH}$ of the nanoparticle suspension was adjusted to 4.5 with $0.5 \mathrm{M}$ sodium hydroxide solution, and the resulting suspension was filtered through a filter membrane $(0.45 \mu \mathrm{m})$. The lecithinchitosan-TPGS nanoparticles (LCT-NPs) suspension was centrifuged at $19000 \mathrm{rpm} \mathrm{min}{ }^{-1}$ for $60 \mathrm{~min}$ at $4{ }^{\circ} \mathrm{C}$, and the supernatant was removed. The pellet was resuspended in $5 \mathrm{~mL}$ of deionized water and centrifuged again. This procedure was performed two times, and then, the nanoparticles were lyophilized for $48 \mathrm{~h}$ with $3 \%$ dextrose as a cryoprotectant and stored at $-20{ }^{\circ} \mathrm{C}$ until use. When EC-LCT-NPs were prepared, the flavonoid (15\%) was dissolved in egg lecithin solution, and the method described above was performed.

Physicochemical characterization of nanoparticles. Particle size and PdI were determined by dynamic light scattering using a Zetasizer Nano ZS90 (Malvern Instruments, USA). The measurements were performed at $25{ }^{\circ} \mathrm{C}$ after reaching the optimal dilution in water of the nanoparticles. The zeta potential was analysed using a capillary cuvette; the measures were performed at $25^{\circ} \mathrm{C}$ by triplicate, and the data are expressed as the mean \pm standard deviation (SD).

Entrapment efficiency and loading of (-)-epicatechin. The amount of (-)-epicatechin loaded (EL) in nanoparticles was determined as follows. Ten milligrams of lyophilized EC-LCTNPs was resuspended in $200 \mu \mathrm{L}$ of bidistilled water and sonicated for $30 \mathrm{~min}$. Then, the sonicate was centrifuged at $20000 \mathrm{rpm}$ for $40 \mathrm{~min}$. The supernatant was recovered and used to quantify the phenolic content by Folin-Ciocalteu (FeC) colorimetric reaction method. ${ }^{23}$ Briefly, $40 \mu \mathrm{L}$ of supernatant was mixed with $800 \mu \mathrm{L}$ of the FeC reactive $(1: 10$ aqueous solution) and incubated for $5 \mathrm{~min}$. Then, $800 \mu \mathrm{L}$ of sodium carbonate $(7 \%)$ was added, mixed and combined with $360 \mu \mathrm{L}$ bidistilled water to reach a final volume of $2 \mathrm{~mL}$. The mix was incubated for $2 \mathrm{~h}$, and the absorbance was measured at $760 \mathrm{~nm}$. The concentration of the phenolic content was calculated from a standard curve that was constructed using (-)-epicatechin. Finally, the percentage of EL in the LCT-NPs and its entrapment efficiency (EE) were calculated according to the following equations: 


$$
\begin{aligned}
& \mathrm{El}=\frac{\mathrm{EE}}{\mathrm{WNPs}} \times 100 \\
& \mathrm{EE}=\frac{\mathrm{EL}}{\mathrm{Ei}} \times 100
\end{aligned}
$$

where EE represents the amount of (-)-epicatechin encapsulated in the nanoparticles, WNPs represent the total weight of the nanoparticles with all their components, and Ei represents the initially added amount (-)-epicatechin.

Fourier transform infrared spectroscopy (FTIR) and atomic force microscopy (AFM). FTIR spectra of chitosan, lecithin, TPGS, (-)-epicatechin, LCT-NPs and EC-LCT-NPs were recorded on an Spectrum 400 FT-IR and FT-NIR Spectrometer (PerkinElmer, USA). Spectra were recorded in a range $4000-350 \mathrm{~cm}^{-1}$ and represent an average of 150 registers with a resolution of 16 . At least three different experiments were performed for each spectrum. AFM was used to visualize the topography of the nanoparticles. A drop of sample was mounted on freshly cleaved mica foil, air dried and then scanned in AFM (Multimode V Veeco, USA). Nanoscope software version 2.1 was used for analysis of the images.

Differential scanning calorimetry. The thermal transition properties of the materials and microparticles were determined using Differential Scanning Calorimetry (DSC). Samples of 3$6 \mathrm{mg}$ were weighed into aluminium crucibles and covered with a pierced lid. The analysis was performed on a DSC Q20 (TA Instruments, Quebec, QC, Canada) from $20-350{ }^{\circ} \mathrm{C}$, with a heating rate of $5{ }^{\circ} \mathrm{C} \mathrm{min}^{-1}$, under an inert nitrogen atmo-

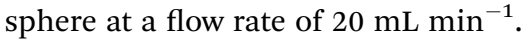

Transmission electron microscopy. The morphology of the CLT-NPs and EC-CLT-NPs was analysed with transmission electron microscopy (TEM) (JEM-2100, JEOL, Japan). A sample was prepared to dilute the nanoparticles tenfold with distilled water, and a drop of the sample was applied onto a Formvarcoated grid (300 mesh, AGAR Scientific, Stansted, United Kingdom). The drop was left in contact with the grid for two minutes to form a thin film. The grid was allowed to dry, the samples were examined, and images were taken using a transmission electron microscope (JEOL, JEM-100CX II).

Cell culture. The cancer cell lines used in this study were obtained from American Type Culture Collection (ATCC) (Manassas, Virginia, USA). MCF-7, MDA-MB-231, SK-BR-3 and MDA-MB-436 are from breast cancer cells. Additionally, the MCF-10A cell line (non-tumorigenic epithelial cell line) was included as normal cells.

MCF-7 and MDA-MB231 cells were grown in DMEM high glucose, while SK-BR-3 and MDA-MB-436 cells were grown in DMEM/F12. The media (Biowest, Riverside-USA) were supplemented with $5 \%$ and $10 \%$ fetal bovine serum (Biowest, Riverside-USA), respectively, $2 \mathrm{mM}$ glutamine, $100 \mathrm{U} \mathrm{mL}^{-1}$ penicillin and $100 \mathrm{mg} \mathrm{mL}^{-1}$ streptomycin.

MCF-10A cells were cultured in DMEM/F-12 supplemented with $5 \%$ horse serum (Biowest USA), $20 \mathrm{ng} \mathrm{mL} \mathrm{mL}^{-1}$ epidermal growth factor (Upstate Biotechnology Incorporated, Lake Placid, $\mathrm{NY}$ ), $10 \mu \mathrm{g} \mathrm{mL}^{-1}$ insulin (Biofluids, Rockville, MD), and $500 \mathrm{ng}$ $\mathrm{mL}^{-1}$ hydrocortisone. All cells were maintained in a humidified incubator at $37{ }^{\circ} \mathrm{C}$ with $5 \% \mathrm{CO}_{2}$.

Cell viability assays. MTT [3-(4,5-dimethylthiazol-2-yl)-2,5diphenyltetrazolium bromide (Sigma)] assays were performed to measure the growth of all cells lines in the presence of (-)-epicatechin and nanoparticles. The inhibitory concentration $50\left(\mathrm{IC}_{50}\right)$ used for the nanoparticles in this study was obtained previously from a dose-response curve using the MDA-MB-231 breast cancer cell line. The cell lines $\left(1 \times 10^{4}\right.$ cells per well) were cultured in $100 \mu \mathrm{L}$ of their respective media in 96 well plates and allowed to attach overnight in a $\mathrm{CO}_{2}$ incubator. The cells were treated with (-)-epicatechin, CLT-NPs and EC-CLT-NPs $\left(\right.$ IC $\left._{50} 85 \mu \mathrm{M}\right)$ for $72 \mathrm{~h}$. Then, MTT $\left(0.5 \mathrm{mg} \mathrm{mL} \mathrm{m}^{-1}\right)$ was added to each well (after aspirating the medium with the nanoparticles), and the plates were incubated for $2 \mathrm{~h}$ at $37{ }^{\circ} \mathrm{C}$ and $5 \% \mathrm{CO}_{2}$. After the medium had been discarded, $150 \mu \mathrm{L}$ of DMSO was applied to each well to dissolve the dark-blue formazan crystals in intact cells. The resulting solution was measured by

\begin{tabular}{|c|c|c|c|c|c|c|}
\hline \multicolumn{7}{|c|}{ Parameters of nanoparticles generation } \\
\hline 0.4 & 0.16 & 10000 & 15 & 10 & 1.5 & 8.75 \\
\hline Features & \multicolumn{4}{|c|}{ LCT-NPs } & \multicolumn{2}{|r|}{ EC-LCT-NPs } \\
\hline $\mathrm{Pdl}^{a}$ & \multicolumn{4}{|c|}{$0.198 \pm 0.02$} & \multicolumn{2}{|r|}{$0.189 \pm 0.01$} \\
\hline Zeta potential $^{a}$ & \multicolumn{4}{|c|}{$0.042 \pm 0.009$} & \multicolumn{2}{|r|}{$-0.054 \pm 0.002$} \\
\hline EL $(\%)$ & & & & & \multicolumn{2}{|r|}{$3.42 \pm 0.85$} \\
\hline EE $(\%)$ & & & & & \multicolumn{2}{|r|}{$56.10 \pm 3.9$} \\
\hline
\end{tabular}

Table 1 Conditions of generation and features of CLT and EC-CLT nanoparticles

${ }^{a}$ Means \pm standard deviation $(n=3)$. LCT-NPs, lecithin-chitosan-TPGS nanoparticles; EC-LCT-NPs, $(-)$-epicatechin-loaded lecithin-chitosanTPGS nanoparticles. TPGS, D- $\alpha$-tocopheryl polyethylene glycol 1000 succinate, PdI, polydispersity index; EL, (-)-epicatechin loaded; EE, entrapment efficiency. 


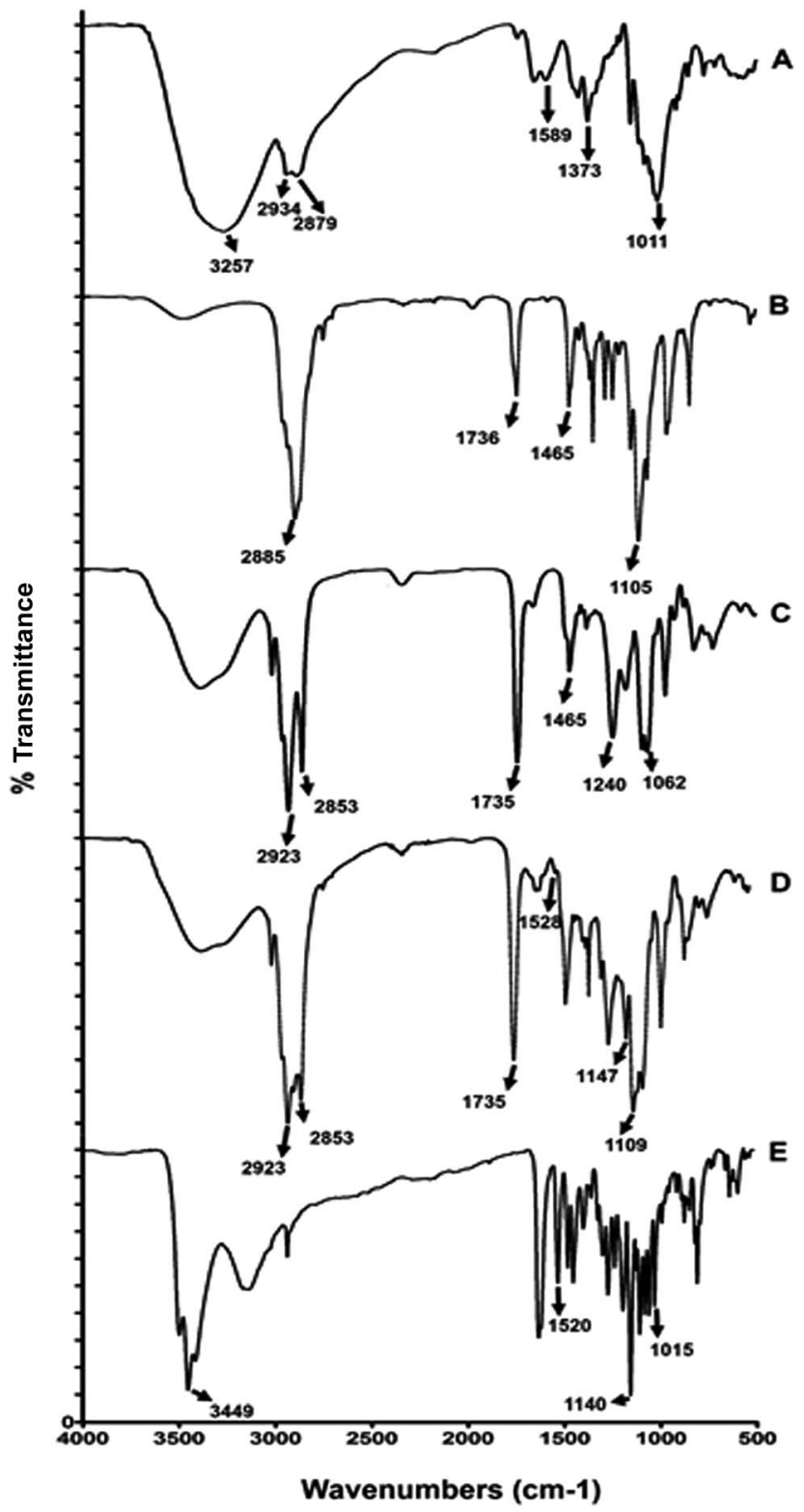

Fig. 2 FTIR spectrum of (A) chitosan, (B) TPGS, (C) lecithin, (D) ECCLT-NPs and (E) (-)-epicatechin.

spectrophotometry with the microplate reader (Synergy HT, BioTek) at a wavelength of $550 \mathrm{~nm}$. Thus, the quantity of formazan produced is directly proportional to the number of living cells. Three different experiments were performed, each data point was in sextuplicate, and the results are reported as the percentage of cells viability \pm standard deviation (SD) in relation to the negative control, the viability of which was designated $100 \%$.

Statistical analysis. We utilized one-way analysis of variance (ANOVA) followed by Tukey's test. Differences were considered statistically significant when $p \leq 0.05$ for the comparative antiproliferative effects among (-)-epicatechin, CLT-NPS and ECCLT-NPs.

\section{Results}

Particle size, polydispersity index and zeta potential

In this study, we used (-)-epicatechin as a molecule attractive to eliminate cancerous cells. Several studies have shown that (-)-epicatechin has an important antiproliferative activity. However, its instability to chemical and physical factors complicate its use. For these reasons, we entrapped (-)-epicatechin in chitosan nanoparticles to generate a form more stable of the molecule. For this purpose, nanoparticles were performed injecting lecithin dissolved in alcohol into an aqueous solution of chitosan. Table 1 shows the parameters used in the generation of nanoparticles, as well as the size, PdI and zeta potential obtained. As can be observed, the presence of the flavonoid increased the size of the nanoparticles, indicating a firm loading of flavonoid on the chitosan. The increase of the nanoparticle was $<200 \mathrm{~nm}$, which indicates their suitability for applications in the cancer treatment. Indeed, evidence indicates that a size less than $<200 \mathrm{~nm}$ could have access into tumor tissues due to the enhanced permeability and retention (EPR effect). ${ }^{24}$ Furthermore, this size allows a long circulation time by a reduction of the opsonization and detection by macrophages. ${ }^{25,26}$

\section{Characterization of nanoparticles}

Fourier transform infrared spectroscopy (FTIR) study. FTIR study was performed to evaluate the chemical interaction of components used in the elaboration of the nanoparticles. These interactions were detected by the variation of peakshape, position and intensity. The FTIR spectra of chitosan, TPGS, lecithin EC-CLTNPs and (-)-epicatechin are shown in Fig. 2. For chitosan and TPGS the functional groups found were the generally used to identify these compounds. Chitosan spectra (Fig. 2A) showed $\mathrm{OH}$ band at $3257 \mathrm{~cm}^{-1}$, amine bands at 2934 and $2879 \mathrm{~cm}^{-1}$, the peak at $1589 \mathrm{~cm}^{-1}$ corresponds to an $\mathrm{N}$ bond and $\mathrm{H}$ bending from the amine and amide II. The peak at $1373 \mathrm{~cm}^{-1}$ corresponds to $\mathrm{CH}_{3}$ symmetrical deformation and the peak at $1011 \mathrm{~cm}^{-1}$ corresponds to the skeletal vibration of $\mathrm{C}$ bond and $\mathrm{O}$ stretching. ${ }^{27-29}$ TPGS spectra (Fig. 2B) showed a peak at 2885 of aromatic $\mathrm{C}-\mathrm{H}$ stretching vibration, a peak at $1736 \mathrm{~cm}^{-1}$ of ester $\mathrm{C}=\mathrm{O}$ stretching, and at $1465 \mathrm{~cm}^{-1}$ a peak due to $-\mathrm{CH}_{2}$ bending vibration. Furthermore, at $1105 \mathrm{~cm}^{-1}$, a peak due to $\mathrm{C}-\mathrm{O}$ stretching characteristic to TPGS. ${ }^{30,31}$ Interestingly, all the absorption bands of chitosan and TPGS were covered in the FTIR spectrum of EC-CLT-NPs. The no detection of chitosan and TPGS bands indicated their incorporation inside of la nanoparticle formed. On the other hand, lecithin, the main component of the nanosystem showed a FTIR spectrum (Fig. 2C) with a peak at $2923 \mathrm{~cm}^{-1}$ and $2853 \mathrm{~cm}^{-1}$ for $\mathrm{C}-\mathrm{H}$ stretching vibration of methylene group, at $1735 \mathrm{~cm}^{-1}$ due to $\mathrm{C}=\mathrm{O}$ stretching vibration, a peak at $1465 \mathrm{~cm}^{-1}$ corresponding to $\mathrm{C}-\mathrm{H}$ bending vibration of methyl group, $1240 \mathrm{~cm}^{-1}$ for $\mathrm{P}=\mathrm{O}$ stretching vibration and $1062 \mathrm{~cm}^{-1}$ for $\mathrm{P}-\mathrm{O}-\mathrm{C}$ stretching vibration. ${ }^{32}$ In this case, the majority lecithin prominent absorption bands also were modifying in the FT-IR spectrum of EC-CLT-NPs (Fig. 2D), except the peak for $\mathrm{C}-\mathrm{H}$ stretching vibration of methylene group (peak 

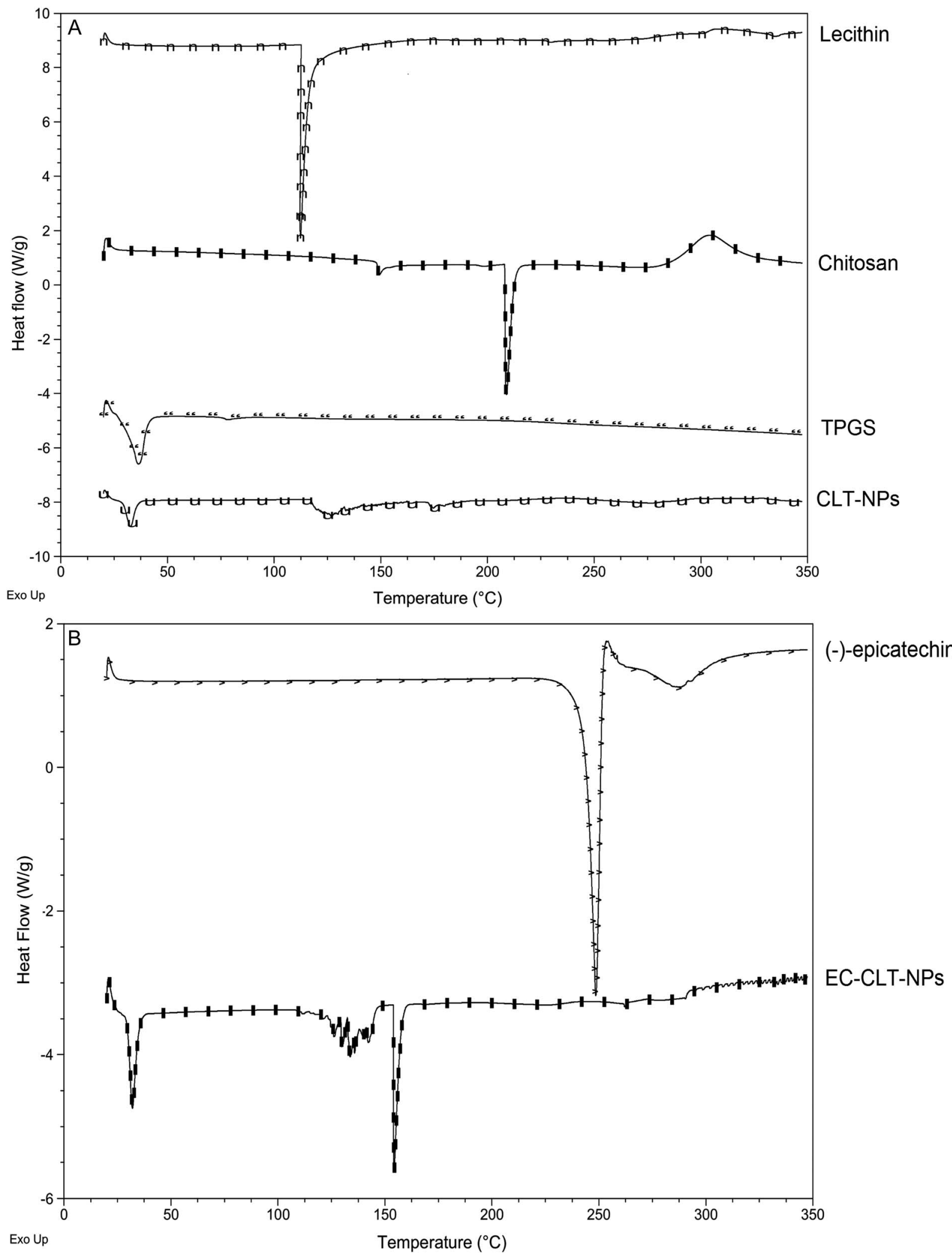

Fig. 3 DSC curves of materials (lecithin, chitosan, TPGS, encapsulation systems (CLT-NPs (A) and (-)-epicatechin and EC-CLT-NPs (B).

$2923 \mathrm{~cm}^{-1}$ and $2853 \mathrm{~cm}^{-1}$ ) and the peak for $\mathrm{C}=\mathrm{O}$ (peak $1735 \mathrm{~cm}^{-1}$ ). These observations indicated that no chemical interaction existed among these groups and the compounds used in the generation of the nanoparticles. Finally, the FTIR spectrum of (-)-epicatechin (Fig. 2E) shows a strong band at $3449 \mathrm{~cm}-1$ due to $-\mathrm{OH}$ groups, a band at $1520 \mathrm{~cm}^{-1}$ shows the aromatic $\mathrm{C}=\mathrm{C}$ group, and the bands at $1140 \mathrm{~cm}^{-1}$ and $1015 \mathrm{~cm}^{-1}$ are characteristic of the $\mathrm{C}-\mathrm{O}-\mathrm{C}$ group. Interestingly, the FTIR spectrum of 


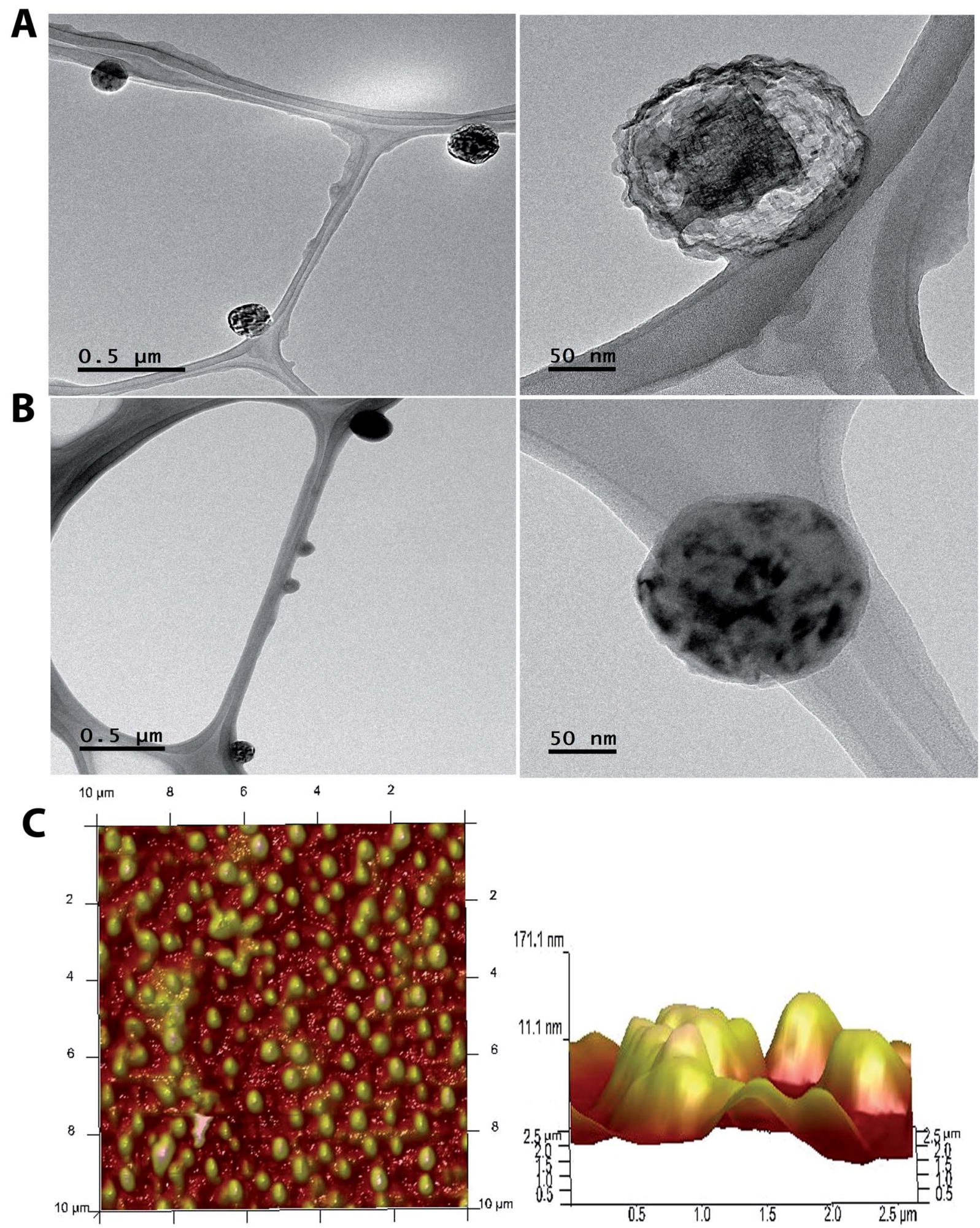

Fig. 4 Transmission electron microscope (TEM) image of CLT-NPs (A), EC-CLT-NPs (B) (weight ratio $38: 1$ ) and atomic force microscopy (ATM) images of EC-CLT-NPs and size (C).

EC-CLT-NPs (Fig. 2D) covered the strong band at $3449 \mathrm{~cm}^{-1}(-\mathrm{OH}$ groups), the no detection or modification of this region indicated the incorporation of epicatechin inside of la nanoparticle and not its encapsulation. In this context, FTIR spectrum of EC-CLT-NPs showed changes at $1528 \mathrm{~cm}^{-1}, 1147 \mathrm{~cm}^{-1}$ and 1109 in comparison with FTIR spectrum of lecithin and epicatechin (Fig. 2D). Indeed, this region in lecithin correspond to $\mathrm{P}-\mathrm{O}-\mathrm{C}$ (peak 1062), $\mathrm{P}=\mathrm{O}$ (peak $1240 \mathrm{~cm}^{-1}$ ), these changes are indicative that ionic 
interactions between phosphate groups of lecithin and compound used in the elaboration of nanoparticles taken place.

\section{Differential scanning calorimetry}

A technique for investigating the thermal properties of a formulation that provides information on the physicochemical state of the drug in the system is the DSC. In this technique, there is no detectable endotherm whether the drug is present in a molecular dispersion or solid state in the polymeric NPs. The DSC thermograms of the materials, CLT-NPs and EC-CLT-NPs are shown in Fig. 3. The DSC curve of chitosan showed a welldefined endothermic peak at $208.43{ }^{\circ} \mathrm{C}$ for chitosan followed by an exothermic peak at $\sim 310{ }^{\circ} \mathrm{C}$ that is defined as a thermal decomposition (Fig. 3A). ${ }^{33}$ On the other hand, TPGS and lecithin showed endothermic peaks at $36.58{ }^{\circ} \mathrm{C}$ and $112.34{ }^{\circ} \mathrm{C}$, respectively (Fig. 3A). The DSC curve of CLT-NPs showed a very small endothermic peak for TPGS and a displacement at $126.83{ }^{\circ} \mathrm{C}$ in the lecithin peak. These data suggest that in CLT-NPs there were significant molecular interactions among the components (Fig. 3A). (-)-epicatechin had an endothermic peak at $248.5{ }^{\circ} \mathrm{C}$ (Fig. 3B), and its loading in CLT-NPs generated a small

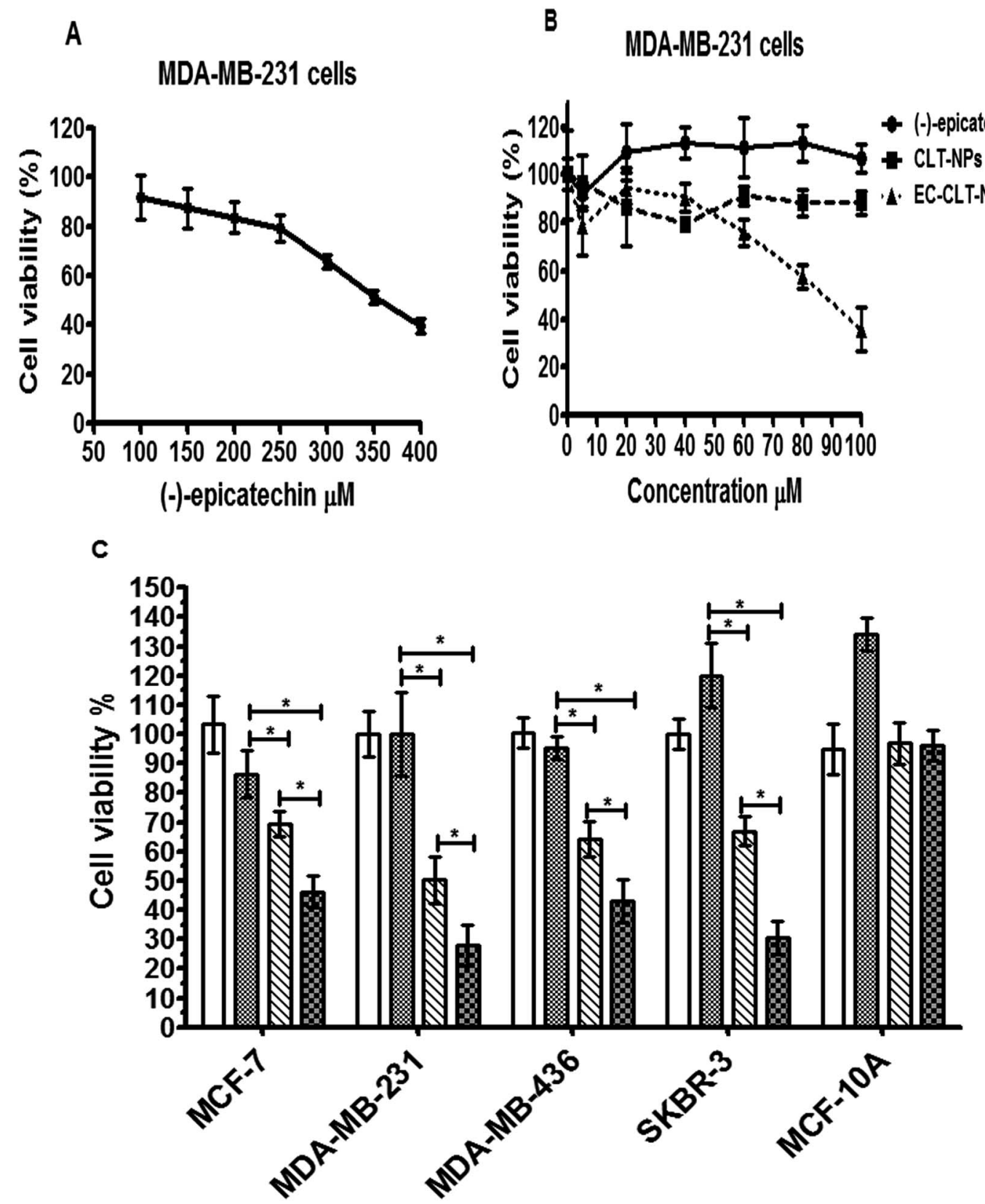

Fig. 5 Cytotoxicity of (-)-epicatechin, CLT-NPs and EC-NPs in breast cancer cells. Cytotoxic effect of free (-)-epicatechin (100-400 $\mu$ M) in MDA-MB-231 (A), cytotoxic effects of (-)-epicatechin, CLT-NPs and EC-CLT-NPs (10-100 $\mu$ M) in MDA-MB-231 (B), comparison of the cytotoxic effects of EC-CLT-NPs, CLT-NPs and free (-)-epicatechin $\left(\mathrm{IC}_{50}=85 \mu \mathrm{M}\right)$ in MCF-7, MDA-MB-231, MDA-MB-436, SKBR-3 breast cancer cells and non-cancerous cells (MCF-10A) (C). Each experiment was conducted three times, each data point was in sextuplicate. Data are presented as mean $\pm \mathrm{SD}(n=3)$ and analyzed by ANOVA (* $p \leq 0.05)$ followed by tukey's test. 
endothermic peak at $154.19{ }^{\circ} \mathrm{C}$ and showed TPGS and lecithin endothermic peaks (Fig. 3B).

\section{Morphology of nanoparticles}

To analyse the size and shape of the nanoparticles generated, we performed a TEM. Representative optical microscopy images of CLT-NPs and EC-CLT-NPs are shown in Fig. 4. As can be observed, they were spherical in shape with an average size of $129.76 \pm 0.83 \mathrm{~nm}$ (Fig. 4A) and $159.76 \pm 2.23 \mathrm{~nm}$ (Fig. 4B) for CLT-NPs and EC-CLT-NPs, respectively. In addition to the uniform size of the nanoparticles, any irregularities or the presence of aggregates was observed. This observation suggested that (-)-epicatechin was captured in lecithin-chitosan matrices. These observations were corroborated by Atomic Force Microscopy (AFM). As shown in Fig. 4C, EC-CLT-NPs exhibited nanospheres with a smooth surface, homogeneous diameters and similar average size (Fig. 4C).

\section{Cytotoxicity assay}

To compare the anticancer activity of (-)-epicatechin versus ECCLT-NPs, we assessed their cytotoxicity on different breast cancer cell lines (MCF-7, MDA-MB-231, MDA-MB-436 and SK-Br3) and noncancerous cells (MCF-10A). First, the effect of (-)-epicatechin $(100 \mu \mathrm{M}$ to $400 \mu \mathrm{M})$ on cell viability was determined through of a concentration-response curve using MDA-MB-231 for 72 hours. The construction of the concentration-response curve reflected a concentration-dependent effect (Fig. 5A). With the curve under logarithmic units, we calculated the inhibitory concentration fifty ( $\mathrm{IC}_{50}$ ) on MDA-MB-231 cells, resulting in $350 \mu \mathrm{M}$ (data not shown). To determine the $\mathrm{IC}_{50}$, MDA-MB-231 cells $\left(1 \times 10^{4}\right.$ cells $)$ were grown with an equivalent amount of EC-CLT-NPs that reached the $\mathrm{IC}_{50}$ of (-)-epicatechin and non-loaded nanoparticles (CLT-NPs). Interestingly, a higher anti-proliferative effect was observed with nanoparticles than (-)-epicatechin over a short period of time (24 h) (data not shown). Due to the highest anti-proliferative effect of nanoparticles, we created a concentration-response curve using MDA-MB-231 cells and different nanoparticle concentrations (10$100 \mu \mathrm{M}$ ) for $72 \mathrm{~h}$ (Fig. 5B). The data obtained shown a concentration-dependent effect with EC-CLT-NPs. Meanwhile, CLT-NPs showed an inhibition constant of $15 \%$, and (-)-epicatechin did not show any anti-proliferative effect (Fig. 5B). Additionally, with this curve in logarithmic units, we calculated the $\mathrm{IC}_{50}$ of EC-CLTNPs on MDA-MB-231 cells, which was $85 \mu \mathrm{M}$ (data not shown). This $\mathrm{IC}_{50}$ was used in the different breast cancer cells lines, and the results are shown in Fig. 4C. As can be observed, (-)-epicatechin with this $\mathrm{IC}_{50}(85 \mu \mathrm{M})$ did not show any effect over $72 \mathrm{~h}$ of incubation, while EC-CLT-NPs generated the highest inhibition of the cell proliferation in all the breast cancer cell lines (MCF-7, MDAMB-231, MDA-MB-436, and SK-BR-3) (Fig. 5C). While CLT-NPs also showed an anti-proliferative effect, this effect was lower than that of EC-CLT-NPs. Because these data could suggest the presence of an ambiguous cytotoxic effect of the nanoparticles, we included in this assay a cell line considered normal mammary cells (MCF-10A). Interestingly, no effect was observed in these cells (Fig. 5C). These results suggest the presence of a selectivity of these nanoparticles to cancerous cells. Fig. 6 shows a representative

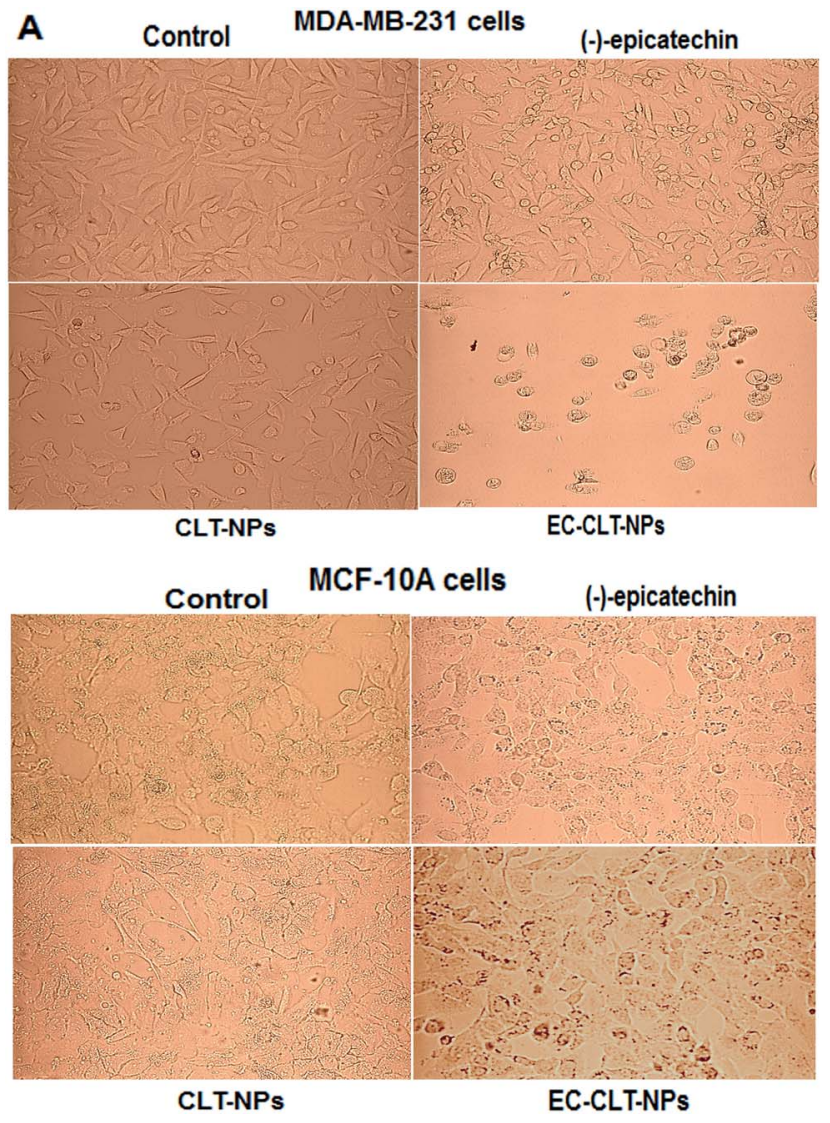

Fig. 6 Selectivity of EC-CLT-NPs to cancerous cells. Effect of the methanol (solvent for (-)-epicatechin) control, (-)-epicatechin, CLTNPs and EC-CLT-NPs on MDA-MB-231 breast cancer cells (A), effect of the same conditions on MCF-10A (non-cancerous cells) (B).

picture of the selectivity of the nanoparticles. Fig. $6 \mathrm{~A}$ shows the effects of the methanol that was used to dissolve (-)-epicatechin (control), (-)-epicatechin, CLT-NPs and EC-CLT-NPs on MDA-MB231 cells. CLT-NPs and EC-CLT-NPs show the effect on cell density and cellular death, respectively. Fig. 6B shows the same condition mentioned above on non-cancerous cells (MCF-10A). No effect on cell density or morphological changes were observed.

\section{Discussion}

Currently, (-)-epicatechin, a non-toxic natural product, has shown anticancer effects cancer; ${ }^{6-8,34}$ however, its high sensitivity to physical and chemical factors limits its therapeutic potential. In this study, we prepared (-)-epicatechin-loaded lecithin-chitosan nanoparticles and evaluated their anticancer activity against breast cancer cells. Regarding this, the injection of an alcohol solution containing lecithin into a chitosan aqueous solution is one of the techniques used for the preparation of nanoparticles. This technique is a thermodynamic process of self-assembly that generates nanoparticles that are well-rounded and have high stability. ${ }^{35,36}$

In the present study, EC-CLT-NPs were generated using a weight ratio of lecithin to chitosan of $38: 1(\mathrm{w} / \mathrm{w})$. Furthermore, TPGS was used to increase (-)-epicatechin solubility and stabilize nanosystems. ${ }^{37-39}$ By this method, EC-CLT-NPs were 
$159 \pm 2.23 \mathrm{~nm}$ in size and had an entrapment efficiency of $56 \%$. Indeed, the higher size of EC-CLT-NPs compared to CLT-NPs indicated the incorporation of (-)-epicatechin. Additionally, the analysis of TEM and AFM of the nanoparticles showed a spherical morphology with a smooth surface. Interestingly, our study demonstrated that the entrapment of (-)-epicatechin in CLT-NPs generates effects such as an increase in the cell cytotoxicity against a panel of human breast cancer cells, a fourfold decrease in the $\mathrm{IC}_{50}$ compared to free (-)-epicatechin and a selectivity to cancerous cells. The advantages obtained with these nanoparticles were probably caused by events such as (1) the protection of (-)-epicatechin and in consequence an enhanced accumulation in the environment of cancer cells, (2) a better intracellular uptake, (3) the presence of a phenomenon amplified by the use of (-)-epicatechin and chitosan, two molecules with anticancer activity, ${ }^{40}$ or (4) a combination of these possibilities.

It is well-known that the generation of nanoparticles as nanocarriers improves many drug parameters. However, more studies are required to understand the mechanism involved in the potentiation of the anticancer activity of EC-CLT-NPs and its selectivity to cancerous cells. Regardless of the mechanism involved, we believed that this potentiation of the anticancer effect of EC-CLT-NPs could be associated with an increase in its anti-tumour effect. At the moment, we are investigating this possibility using animal models. Moreover, we are looking for an appropriate targeting ligand that can be conjugated to the nanoparticle surface to target a specific tumour. These approaches will explore the use of EC-CLT-NPs as an alternative or adjuvant in breast cancer therapy.

In this context, considering that breast cancer is the main cause of the high mortality rate in women and that various drugs used in the therapy have limited action due to their high toxicity, ${ }^{41,42}$ the development of novel agents for the treatment of breast cancer is highly regarded. ${ }^{43}$ In our study, we showed that EC-CLT-NPs greatly improve (-)-epicatechin's properties against breast cancer. These nanoparticles were capable of inhibiting the cell proliferation of a wide range of breast cancer cell such as estrogen receptor positive (ER+) (MCF-7), cells that overexpresses the HER2/c-erb-2 gene product (SK-BR-3) and triple negative breast cancer cells $[\operatorname{ER}(-)$, progesterone $(-)$ and HER2(-)]. These results are consistent with prior reports that demonstrated that (-)-epicatechin affects cell growth in breast cancer cell lines. ${ }^{34}$ Furthermore, based on the data obtained in our study, (-)-epicatechin loaded chitosan-lecithin nanoparticles have a stronger inhibitory effect on breast cancer cells in comparison with free (-)-epicatechin. To our knowledge, this is the first time it has been demonstrated that loading (-)-epicatechin in CLT-NPs improves the inhibitory effects of (-)-epicatechin. Finally, we considered that several biological activities of (-)-epicatechin have been described. The nanoparticles could be a good nanocarrier system to deliver (-)-epicatechin to a specific site. Indeed, the search for an appropriate targeting ligand that can be conjugated to the nanoparticle surface to target a specific site (tumour, muscle, heart, etc.) could be helpful in addressing (-)-epicatechin. The main text of the article should appear here with headings as appropriate.

\section{Conclusions}

The present study described the generation of (-)-epicatechinloaded lecithin-chitosan nanoparticles. Furthermore, revealed that these nanoparticles have an inhibitory effect on human breast cancer cell line to a greater degree than free (-)-epicatechin. Although, this inhibition was in a wide range of breast cancer cell such as estrogen receptor positive $(\mathrm{ER}+)$, cells that overexpresses the HER2/c-erb-2 gene product and triple negative breast cancer cells [ER(-), progesterone $(-)$ and HER2(-)], the nanoparticles showed a selectivity to cancerous cells. In addition, the loaded of (-)-epicatechin in this nanoparticle generated an $\mathrm{IC}_{50}$ that was four-fold lower than free (-)-epicatechin. Finally, whether in vivo studies confirm the efficacy of EC-LCT-NPs and modifications can be made in the surface of the nanoparticle to direct these to cancer cells, it could be considered in a clinical study in patients with breast cancer in the future.

\section{Conflicts of interest}

There are no conflicts of interest to declare.

\section{Acknowledgements}

Centro de Nanociencias y Micro y Nanotecnologías del IPNMéxico for assistances in microscopy characterization. Dr Francisco Hernández Luis, Departamento de Farmacia, Facultad de Química, UNAM and Q. Marisela Gutiérrez Franco, Unidad de Servicios de Apoyo a la Investigación y a la Industria (USAII), Facultad de Química UNAM for assistences in FTIR. This research was financially supported by a Grant SIP: 20161601, 20171367 from Instituto Politécnico Nacional.

\section{References}

1 M. Demeule, J. Michaud-Levesque, B. Annabi, D. Gingras, D. Boivin, J. Jodoin, S. Lamy, Y. Bertrand and R. Béliveau, Curr. Med. Chem.: Anti-Cancer Agents, 2002, 2, 441-463.

2 J. Hu, D. Webster, J. Cao and A. Shao, Regul. Toxicol. Pharmacol., 2018, 95, 412-433.

3 A. C. Aprotosoaie, S. V. Luca and A. Miron, Compr. Rev. Food Sci. Food Saf., 2016, 15, 73-91.

4 C. G. Fraga, M. C. Litterio, P. D. Prince, V. Calabro, B. Piotrkowski and M. Galleano, J. Clin. Biochem. Nutr., 2010, 48, 63-67.

5 P. Iacopini, M. Baldi, P. Storchi and L. Sebastiani, J. Food Compos. Anal., 2008, 21, 589-598.

6 A. Othman, A. M. M. Jalil, K. K. Weng, A. Ismail, N. A. Ghani and I. Adenan, Afr. J. Biotechnol., 2010, 9, 1052-1059.

7 P. C. de P. Vasconcelos, L. N. Seito, L. C. Di Stasi, C. A. Hiruma-Lima and C. H. Pellizzon, J. Evidence-Based Complementary Altern. Med., 2012, 1-12.

8 H. Schroeter, C. Heiss, J. Balzer, P. Kleinbongard, C. L. Keen, N. K. Hollenberg, H. Sies, C. Kwik-Uribe, H. H. Schmitz and M. Kelm, Proc. Natl. Acad. Sci. U. S. A., 2006, 103, 1024-1029. 
9 D. Kim, M. L. Mollah and K. Kim, Anticancer Res., 2012, 32, 5353-5362.

10 M. A. Papiez, J. Baran, K. Bukowska-Straková and W. Wiczkowski, Food Chem. Toxicol., 2010, 48, 3391-3397.

11 J. Shay, H. A. Elbaz, I. Lee, S. P. Zielske, M. H. Malek and M. Hüttemann, Oxid. Med. Cell. Longevity, 2015, 1-13.

12 P. V. Gadkari and M. Balaraman, Food Bioprod. Process., 2015, 93, 122-138.

13 A. R. Bilia, B. Isacchi, C. Righeschi, C. Guccione and M. C. Bergonzi, Food Nutr. Sci., 2014, 5, 1212-1227.

14 A. Granja, M. Pinheiro and S. Reis, Nutrients, 2016, 8, 307.

15 A. Kumari, S. K. Yadav and S. C. Yadav, Colloids Surf., B, 2010, 75, 1-18.

16 M. P. Patel, R. R. Patel and J. K. Patel, J. Pharm. Pharm. Sci., 2010, 13, 536-557.

17 M. Dash, F. Chiellini, R. M. Ottenbrite and E. Chiellini, Prog. Polym. Sci., 2011, 36, 981-1014.

18 R. Kumar and O. P. Katare, AAPS PharmSciTech, 2005, 6(2), E298-E310.

19 T. Mengoni, M. Adrian, S. Pereira, B. Santos-Carballal, M. Kaiser and F. M. Goycoolea, Pharmaceutics, 2017, 9, 56.

20 A. Hafner, J. Lovrić, I. Pepić and J. Filipović-Grčić, J. Microencapsulation, 2011, 28, 807-815.

21 Y. Guo, M. Chu, S. Tan, S. Zhao, H. Liu, B. O. Otieno, X. Yang, C. Xu and Z. Zhang, Mol. Pharm., 2014, 11, 59-70.

22 F. Sonvico, A. Cagnani, A. Rossi, S. Motta, M. T. Di Bari, F. Cavatorta, M. J. Alonso, A. Deriu and P. Colombo, Int. J. Pharm., 2006, 324, 67-73.

23 G. A. Agbor, J. A. Vinson and P. E. Donnelly, Int. J. Food Sci., Nutr. Diet., 2014, 3, 147-156.

24 H. Maeda, J. Drug Targeting, 2017, 25(9-10), 781-785.

25 J. Gong, M. Chen, Y. Zheng, S. Wang and Y. Wang, J. Controlled Release, 2012, 159(3), 312-323.

26 N. Nishiyama and K. Kataoka, Pharmacol. Ther., 2006, 112(3), 630-648.
27 G. Lawrie, I. Keen, B. Drew, A. Chandler-Temple, L. Rintoul, P. Fredericks and L. Grøndahl, Biomacromolecules, 2007, 8, 2533-2541.

28 P. Li, Y.-N. Dai, J. P. Zhang, A.-Q. Wang and Q. Wei, Int. J. Biomed. Sci., 2008, 4, 221-228.

29 Y. Luo, B. Zhang, W.-H. Cheng and Q. Wang, Carbohydr. Polym., 2010, 82, 942-951.

30 R. A. H. Ishak and R. Osman, Int. J. Pharm., 2015, 485, 249260.

31 T. Wan, J. Pan, Y. Long, K. Yu, Y. Wang, W. Pan, W. Ruan, M. Qin, C. Wu and Y. Xu, Int. J. Pharm., 2017, 528, 511-523.

32 X. Wang, Z. Luo and Z. Xiao, Carbohydr. Polym., 2014, 101, 1027-1032.

33 D. de Britto and S. P. Campana-Filho, Thermochim. Acta, 2007, 465, 73-82.

34 A. A. Alshatwi, J. Exp. Clin. Cancer Res., 2010, 29, 167.

35 T. Şenyiğit, F. Sonvico, S. Barbieri, Ö. Özer, P. Santi and P. Colombo, J. Controlled Release, 2010, 142, 368-373.

36 A. Fakhry, G. B. Schneider, R. Zaharias and S. Senel, Biomaterials, 2004, 25, 2075-2079.

37 Y. Gao, L. B. Li and G. Zhai, Colloids Surf., B, 2008, 64, 194199.

38 L. Gao, D. Zhang, M. Chen, C. Duan, W. Dai, L. Jia and W. Zhao, Int. J. Pharm., 2008, 355, 321-327.

39 L. Mu and P. H. Seow, Colloids Surf., B, 2006, 47, 90-97.

40 L. Qi and Z. Xu, Bioorg. Med. Chem. Lett., 2006, 16, 42434245.

41 J.-A. W. Chapman, D. Meng, L. Shepherd, W. Parulekar, J. N. Ingle, H. B. Muss, M. Palmer, C. Yu and P. E. Goss, J. Natl. Cancer Inst., 2009, 100, 252-260.

42 S. Raj, V. I. Franco and S. E. Lipshultz, Curr. Treat. Options Cardiovasc. Med., 2014, 16, 314-328.

43 N. Carels, L. B. Spinassé, T. M. Tilli and J. A. Tuszynski, Theor. Biol. Med. Modell., 2016, 13, 7. 